\title{
Comparative Analysis on Storability of Different Prune Fruit Production in Xinjiang
}

\author{
Renaguli·Musha, Zhang Hong, Shangeyili·Bayier \\ College of Food Science and Pharmaceutical Science, Xinjiang Agricultural University, Urumqi, China
}

\section{Email address:}

renagulm@sina.com (Renaguli·Musha)

\section{To cite this article:}

Renaguli $\cdot$ Musha, Zhang Hong, Shangeyili Bayier. Comparative Analysis on Storability of Different Prune Fruit Production in Xinjiang. Science Discovery. Vol. 4, No. 4, 2016, pp. 249-252. doi: 10.11648/j.sd.20160404.18

Received: June 10, 2016; Accepted: July 18, 2016; Published: July 25, 2016

\begin{abstract}
French, Record, Lanmi, Xinzilan and Great rosa 5 prune fruits production in Xinjaing were used as materials, the fruits stored in the cold storage $\left(4^{\circ} \mathrm{C}\right)$ for $35 \mathrm{~d}$ after treated with $1-\mathrm{MCP}$ and comparative analysis the storability of different prune fruits. The results showed the single fruit size of Lanmi is the largest, while the single fruit of French is the smallest. The hardness of Xinzilan and Lanmi fruits is greater than other varieties of prune fruits. The vitaminC and total acid contents higher in French fruit than in other varieties of prune fruits. The fruits of Xinzilan showed high hardness, respiration rate and decay rate is low, storability better than the other varieties of prune fruits.
\end{abstract}

Keywords: Prune, 1-MCP, Respiration Rate, Decay Rate, Storage Ability

\section{新疆不同品种西梅耐栬性比较分析}

\section{热娜古丽・木沙, 张红, 山格依里・巴依尔 \\ 新疆农业大学, 食品科学与药学学院, 新疆乌鲁木齐, 中国}

邮箱:

renagu1m@sina.com（热娜古丽・木沙）

摘要：以法兰西、来客、兰密、新紫兰和大玫瑰 5 个新疆西梅品种为试验材料, 均采用 1 -甲基环丙烯（1-MCP）处理后 置于 $4^{\circ} \mathrm{C}$ 冷库败藏 $35 \mathrm{~d}$, 比较分析其耐咜性。结果表明, 西梅果单颗重兰米为最大, 法兰西为最小; 新紫兰和兰米的硬 度大于其它品种; 法兰西的维生素C含量和总酸含量高于其它品种。新紫兰表现出硬度大、呼吸强度和腐烂率低, 耐咜 性优于其它品种。

关键词：西梅，1-MCP，呼吸强度，腐烂率，耐它性

\section{1. 引言}

西梅, 植物学上称之为欧洲李 (Prunus domestica L. ), 为蓄薇科 (Rosaceae) 李属果树树种之一。在国内 称西梅或欧洲李 $[1]$ 。西梅的小果型品种有法兰西、大玫 瑰等, 大果型品种有兰密、新紫兰、来客、龙萨 [2]等。 西梅果实多为卵圆或圆形; 颜色多为深蓝色或深紫红色。
西梅果实富含多种果香（柿子、菠萝等）、口感浓甜, 果 核小, 果肉细㖑 [3]。另外, 西梅果实中含有丰富的维生 素、矿物质及食物纤维素等, 是现代人健康饮食的最佳果 品 [4]。近年研究表明, 西梅中含有大量的抗氧化物质, 且不含脂肪和胆固醇, 经常食用西梅可起到延缓机体和大 脑衰老的功效 [5-6]。杨艳等 [7]研究证明西梅汁对自然衰 老小鼠抗氧化能力的影响。也有研究提示, 西梅汁有延缓 
衰老的作用 [8-9]。西梅鲜果属于水分含量高, 贮藏性差, 呼吸跃变型果实, 成熟季节集中, 收获时气温较高, 常温 下很快软烂, 影响市场销售和消费。低温咜藏可降低果实 采后呼吸速率及内源乙烯的生成。西梅鲜果对乙烯非常敏 感 [10], 若能最大程度上抑制采后西梅中乙烯的催熟作用, 对延长西梅的保质期将有重大意义。1-MCP是一种新型的 乙烯作用抑制剂, 可与果蔬组织中的乙烯受体发生不可逆 性的结合从而阻断乙烯与受体的结合 [11]。研究表明, 1-MCP可以延长蓝莓 [12]、蜜桃 [13]、马铃薯 [14]、猕猴 桃 [15]等多种果蔬败藏保鲜期, 提高果蔬的保鲜品质。本 研究以 5 个新疆西梅品种为试验材料, $1-\mathrm{MCP}$ 处理之后的西 梅放置于 $4^{\circ} \mathrm{C}$ 冷库贮藏, 定期测定其硬度、总酸含量、维 生素C含量、呼吸度等指标, 对不同西梅品种之间的耐咜 性进行比较研究。

\section{2. 材料与方法}

\section{1 . 材料}

5 个西梅品种, 即法兰西 (French)、来客（Record）、 兰密 (Lanmi)、新紫兰 (Xinzilan) 和大玫瑰 (Great rosa) 均取自于新疆阿克陶县。挑选大小均匀、无病虫害的果实 进行处理。1-甲基环丙烯粉剂 (0.14g/包 即 1-MCP气体浓 度为 $1.0 \mu \mathrm{L} / \mathrm{L}$ ，产于美国Agro-fresh公司）。

\section{2. 测定指标及方法}

\subsection{1. 感官评价}

感官评价参考牛云蔚 [16]樱桃酒感官评价与电子舌 感官分析的相关性研究, 对5个西梅品种的大小、颜色、 单颗重量、口感等进行评价。

\subsection{2. 试验设计}

本试验参考陈嘉 [17]1-甲基环丙烯对李的品质影响, 选用1. $0 \mu \mathrm{L} / \mathrm{L} 1-\mathrm{MCP}$ 处理西梅鲜果。将每个品种西梅果实随 机分成 2 组 (实验组和对照组) 且每组均设置 3 个重复, $1 \mathrm{~kg}$ / 箱, 实验组中每箱放入一包 $1-\mathrm{MCP}$ 粉剂。用厚度为 $0.04 \mathrm{~mm}$ 的聚乙烯塑料薄膜保鲜袋包装, 储藏在温度为 $4^{\circ} \mathrm{C}$, 相对 湿度为 $70 \%-80 \%$ 的冷库中, 定期取样供分析。

\subsection{3. 相关指标}

水分含量采用恒温烘干法（GB 5009. 3-2010）测定; 果肉的硬度使用GY1型果实硬度计测定 $[18]$; 总酸含量采 用滴定法GB/T 15038-2006[19]测定; 可溶性固形物采用 手持式折光仪法测定; 水解后还原糖采用斐林试剂滴定法 测定; 呼吸强度采用静置法测定; 维生素C含量采用 $2,6-$ 二氯酚静酚比色法 (GB / T 6195-1986) [20］测定; 腐烂率 以果肉质地坡塌、发生霉变为界定, 利用以下公式计算:

果实腐烂率 $/ \%=$ (烂果数 $/$ 总果数 $) \times 100$

\section{2. 4. 数据处理} 件处理。

\section{3. 结果与分析}

\section{1. 不同西梅品种的感官指标}

西梅5个品种外观及成分比较分析结果见表 1 。法兰西 品种的果实较小, 颜色呈玫瑰红, 皮薄且酸甜可口; 大玫 瑰与法兰西品种颜色相近，果实较大，体积为法兰西的 2 倍, 甜度低于法兰西; 来客、兰密和新紫兰品种果实较大, 平均体积在 $60 \sim 80 \mathrm{~cm}^{3}$, 皮厚, 颜色深, 味道较酸, 口感 较差于法兰西和大玫瑰品种。

表1 不同西梅品种采摘时的外观及成分特点。

\begin{tabular}{llllll}
\hline 品种 & 法兰西 & 来客 & 兰密 & 新紫兰 & 大玫瑰 \\
\hline 体积 $\left(\mathrm{cm}^{3}\right)$ & $23 \sim 27$ & $70 \sim 75$ & $78 \sim 83$ & $60 \sim 65$ & $40 \sim 50$ \\
单颗重量 $(\mathrm{g})$ & $17 \sim 25$ & $65 \sim 75$ & $75 \sim 80$ & $65 \sim 70$ & $50 \sim 60$ \\
果皮颜色 & 玫瑰红 & 蓝黑色 & 蓝黑色 & 蓝黑色 & 鲜红色 \\
果肉颜色 & 橙黄色 & 橙黄色 & 黄色 & 橙黄色 & 黄色 \\
硬度 $\left(\mathrm{kg} / \mathrm{cm}^{2}\right)$ & 1.47 & 1.08 & 2.10 & 2.18 & 1.35 \\
可溶性固形物 $(\%)$ & 13.0 & 16.2 & 14.0 & 13.8 & 15.6 \\
$\mathrm{pH}$ & 3.65 & 3.73 & 3.90 & 3.80 & 3.60 \\
可滴定酸 $(\%)$ & 1.68 & 0.84 & 1.26 & 0.69 & 0.63 \\
水解后还原糖 $(\%)$ & 14.40 & 8.80 & 8.70 & 8.60 & 9.80 \\
$\mathrm{~V}_{c}$ 含量 $(\mathrm{mg} / 100 \mathrm{gFW})$ & 6.48 & 4.82 & 0.55 & 1.34 & 3.95 \\
\hline
\end{tabular}

\section{2. 不同西梅品种在贮藏其间的硬度变化}

随着贮藏时间的延长, 各西梅品种的硬度均呈下降趋 势, 但在最初 14 天较缓慢, 随后呈快速下降（图1）。新 紫兰和兰密品种的硬度较大, 整个伧藏期硬度下降速度明 显缓于其它品种。

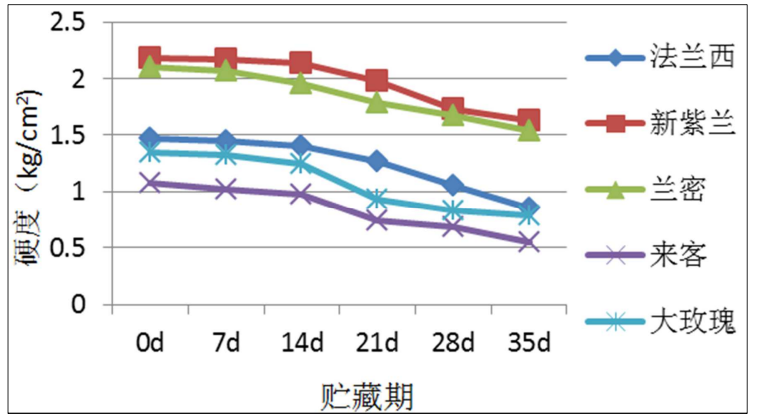

图1 不同西梅品种败藏期间硬度变化 (\%)。

\section{3. 不同西梅品种在贮藏其间的总酸含量变化}

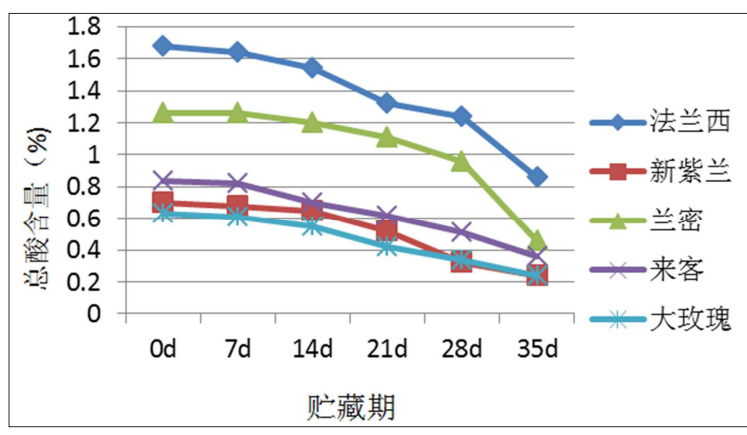

图2 不同西梅品种贮藏期间总酸含量变化 (\%)。 
5 个品种西梅的总酸含量变化如图2所示。法兰西品种 的总酸含量高于其它品种。随着拒藏时间的延长, 总酸含 量均呈下降趋势, 但最初 7 天时间内下降速率缓慢。败藏 后期, 除法兰西以外其它品种的总酸含量无明显变化。

\section{4. 不同西梅品种在贮藏其间的维生素C含量的变化}

各西梅品种的维生素C含量变化如图3所示。法兰西品 种的维生素C含量最高, 兰密和新紫兰最低。在败藏前 21 天时, 维生素C含量均无明显变化, 其后呈下降趋势。

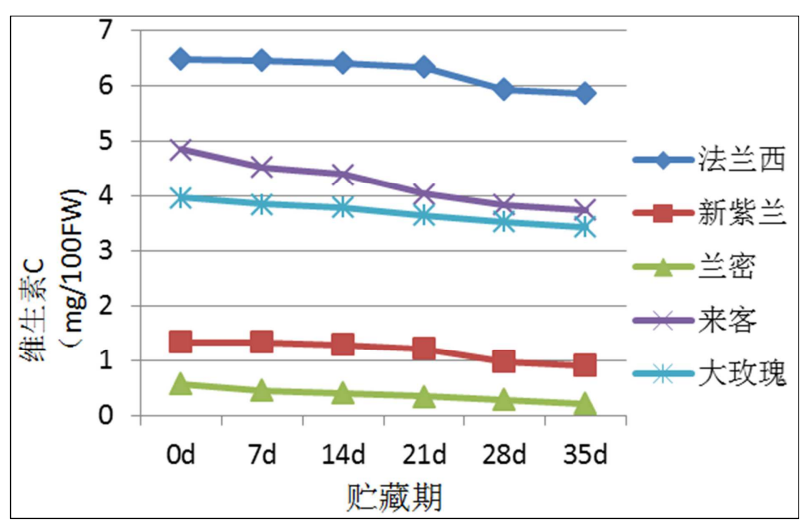

图3 不同西梅品种贮藏期间维生素C含量变化 (\%)。

\section{5. 不同西梅品种在贮藏其间的呼吸强度变化}

随着咜藏时间的延长, 各西梅品种的呼吸强度均呈下 降趋势, 但最初14天呈快速下降, 随后无明显变化 (图4)。 法兰西品种的呼吸速率为最高, 来客和兰密较缓慢。

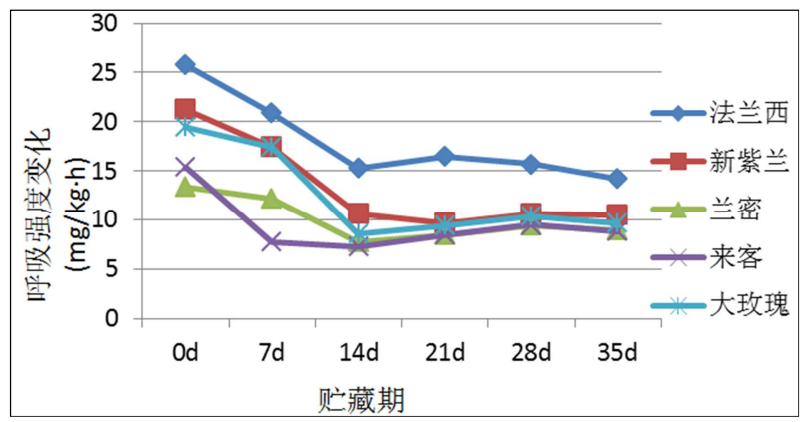

图4 不同西梅品种伧藏期间呼吸强度变化 $(\mathrm{mg} / \mathrm{kg} \cdot \mathrm{h})$ 。

\section{6. 不同西梅品种在贮藏其间的腐烂率}

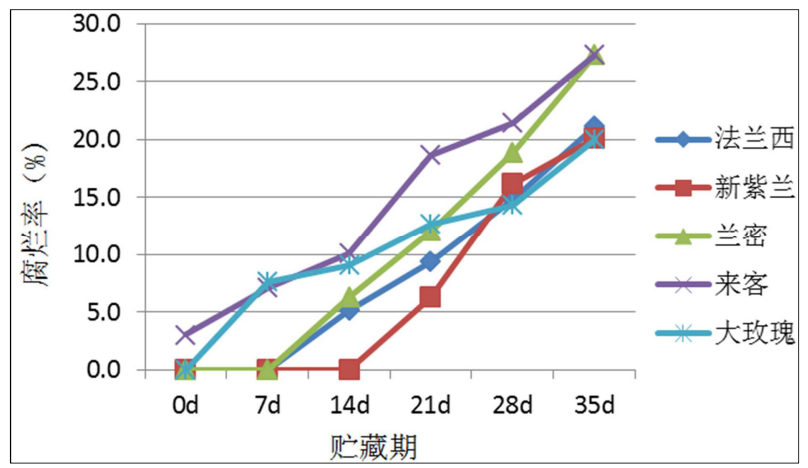

图5 不同西梅品种伧藏期间腐烂率变化 (\%)。
败藏前 7 天时, 兰密和来客出现腐烂, 但新紫兰、大 玫瑰和法兰西品种均未出现腐烂（图5）。㫟藏至第 14 天 时, 新紫兰仍未出现腐烂现象。咜藏第 21 天至 35 天时, 所 有品种的腐烂率均呈上升趋势, 来客的腐烂率为最高, 达 到 $25 \%$ 以上。

\section{4. 讨论}

低温冷藏保鲜是利用低温降低果蔬的呼吸作用, 减少 能量的耗散, 抑制微生物的生长, 延缓果蔬的腐烂速度, 达到保鲜效果。1-MCP广泛运用于多种水果及蔬菜的咜藏 保鲜, 其优点为中毒性低, 对人、牲畜以及环境均无污染, 且使用量少、处理数量大, 使用安全、方便等 $[21]$ 。张克 宏等 [22]研究表明1-MCP 能降低败藏期鲜果的呼吸作用, 酸、VC含量、果实硬度变化较小。

本研究以新疆阿克陶县生产 5 个西梅品种的鲜果实 为实验材料, 比较分析其在 $1-\mathrm{MCP}$ 处理并在低温下的耐 藏性差异。研究发现, 随着咜藏时间的延长, 硬度、总 酸含量均以缓慢趋势下降, 维生素C含量在拒藏前 21 天 时无明显变化, 其后也呈下降趋势。但相对于其它品种, 新紫兰和兰密品种的硬度较大, 下降速度明显缓于其它 品种, 通过 $35 \mathrm{~d}$ 的珂藏期后, 其硬度仍然大于其它三个 品种。采收成熟度是影响果实栬藏品质和它藏期长短的 主要因素之一 [23]。Guerra and Casquero[24]的研究 结果表明, 西梅品种Green Gage采摘时的成熟度与其品 质之间有重要关系。新紫兰和兰密品种的硬度较大与该 品种在同一采摘时间的成熟度有关。呼吸作用越旺盛, 其生物体内的各种复杂的生理生化变化也会随之加快, 果实贮藏寿命也就越早终止 [25]。呼吸强度在最初 14 天 呈快速下降, 但总体上除法兰西以外的其它品种间随后 无明显变化。各西梅品种果实腐烂率均在陉藏后期迅速 上升, 来客的腐烂率达到 $25 \%$ 以上。但陉藏至第 $14 \mathrm{~d}$ 时, 新紫兰仍未出现腐烂现象, 聍藏 $21 \mathrm{~d}$ 时腐烂率仅在 $5 \%$ 左 右。综上结果表明, 新紫兰是适宜做大规模商业䛎藏的 西梅品种。

\section{5. 结论}

1. 5 个品种西梅果实的性状存在相似之处, 多呈卵圆 或椭圆形, 果肉多呈橙黄色, 来客、兰密和新紫 兰呈蓝黑色。

2. 新紫兰和兰密的硬度优于其它品种, 而法兰西的 维生素C含量和总酸含量高于其它品种。

3. 随着穴藏时间的延长, 西梅鲜果的总酸含量均以 缓慢趋势下降, 维生素C含量在败藏前 21 天时无明 显变化, 其后也呈下降趋势。呼吸强度在最初 14 天呈快速下降, 随后无明显变化。

4. 新紫兰表现出硬度大、呼吸强度和腐烂率低, 耐 贮性优于其它品种, 是适宜做大规模商业聍藏的 西梅品种。 


\section{致谢}

本文为省科研项目《西梅优质果品精深加工技术研究, XJLK（2013) 006》的阶段性成果之一。

\section{参考文献}

１］王斐，卢春生，张平，等. 欧洲李不同品种授粉结实性试验 研究 $[J]$. 新疆农业科学, 2010，6 (47) : 1081-1083。

[2] 谭坚. 美容瘦身西梅馔三款 $[\mathrm{J}]$. 东方食疗与保健, 2005, (12) : $15-16$ 。

[3] 宋绪子. 西梅在渭河沿岸的栽培表现 [J]. 西北园艺, 2006, 12 (6) : $37-39$ 。

[4] 林培钧, 皮里东. 美国加州西梅（欧洲李）及其在新疆的开 发 $[\mathrm{J}]$. 北方果树, 2003, 3(5):1-3。

[5] 陈磊. 西梅籽 $\mathrm{b}$-葡萄糖苷酶的分离纯化、性质及固定化研 究 $[J]$. 医学理论与实践, 2013, 6(26) :707-710。

[6] Krause G, Weis E. Chlorophyll fluorescence and photosynthesis:The basics annual review of plant. Annual Review of Plant Physiology and Plant Molecular Biology, 1991, 42:313-349.

[7] 杨艳, 陈润, 王琼. 西梅汁抗氧化作用动物实验研究 [J]. 医学理论与实践, 2013，26（6）:707-710。

[8] 李如琛. 氧自由基致病机理与抗氧化物 $[J]$. 日本医学介绍, 2001, 16 (6) :282-283。

[9] Collins A. Oxidative DNA damage, antioxidants and cancer [J]. Bioessays, 1999, 21 (3) :238-246。

[10] 周龙, Carolyn DeBuse, John E. Preece. 美国加州西梅产 业化发展现状分析 [J]. 中国果树, 2014, (4) :82-84。

[11] 杨健, 李秀根. 西梅丰产优质栽培技术 $[\mathrm{J}]$. 山西果 树, 2001, 7(1):10-12。
[12］纪淑娟, 周倩, 马超, 等. 1-MCP处理对蓝莓常温货架品质 变化的影响 $[\mathrm{J}]$. 食品科学, 2014, 35 (02) : 322-327。

[13] 及华, 关军锋, 冯云霄, 等. 1-MCP和预拒对深州蜜桃采后 生理和品质的影响 [J]. 食品科学, 2014, 35 (14) : 247-250。

[14] ᄀ小琴, 关海宁, 魏雅冬. 1-甲基环丙烯处理对窝藏马铃薯 的保鲜效果 $[J]$. 食品工业科技, 2014, 35 (06) : 303-306。

[15] 郭叶, 王亚萍, 费学谦, 等. 1-甲基环丙烯处理对 “徐香” 猕猴桃储藏保鲜效果的影响 $[\mathrm{J}]$. 浙江农林大学学报, 2013, 30 (3) : 364-371。

[16] 牛云蔚, 张晓鸣, 肖作兵, 等. 樱桃酒感官评价与电子舌感官 分析的相关性研究 [J]. 食品工业科技, 2012, 33 (16) : 105-107.

[17] 陈嘉, 张立新, 冯志宏, 等. 婴藏温度和1-甲基环丙烯对四 川青脆李褐变的影响 [J]. 食品工业科技, 2014, $35(2): 312-323$.

[18] 贾晓辉, 佟伟, 王文辉, 夏玉静, 张志云, 姜云斌. 1-MCP、 MAP 对苹果冷藏期间品质及保鲜效果的影响 [J]. 食品科学, 2011，32（08）:305-308。

[19] 张意静. 食品分析. [M]. 北京: 中国轻工业出版社, 1995。

[20] 黄玉琴, 谢天柱, 王风霞. 测定果蔬中维生素C含量的方法比 较 $[J]$. 落叶果树 $2013,45(2): 08-11$ 。

[21] 朱金薇, 冯江涛, 王浩, 等. 1-甲基环丙烯对枇杷咜藏品质 的影响 $[J]$. 现代园艺, 2013, 11(8):14-17。

[22] 张克宏, 杜俊娟. 1-MCP对猕猴桃包装陉藏生理的影响研究 $[J]$. 食品科学, 2007, 28 (11) :575-579。

[23] 韩涛, 李丽萍, 葛兴. 热激处理对冷藏桃果实的生理效应. 植 物生理学通讯, 19\%, 32(3): 184-186。

[24] Guerra M , Casquero P. Site and fruit maturity influence on the quality of European plum in organic production. Scientia Horticulturae [J]. Food Egineering, 2009, 122:540-544.

[25] 饶景萍. 园艺产品咜运学 [M]. 北京: 科学出版社, 2009。 